\title{
Construction of an Inclusive Learning Environment: Towards a New Ecological Class
}

\author{
Bagnariol Silvio* \\ Cà Foscari University, Venice, Italy \\ *Corresponding author: silviobagnariol@hotmail.com \\ Received July 08, 2015; Revised July 19, 2015; Accepted July 20, 2015
}

\begin{abstract}
The Italian school inclusion and integration process still involve considerable troubles and difficulties: "integration is not at issue, yet it is often unsatisfactory" [1]. Junior high school and high school students with intellectual disability tend to take little part in the learning process or, even worse, to remain in a situation of separation most of the time [2]. This two-group experimental study focused on six classes from a vocational high school. The assumption was that a learning environment expressly designed [3] to encourage analogical tools, processes and languages can effectively help all students - not only students with intellectual disability - to learn and to relate better. The "ecological approach" [4], started from a rearrangement of the traditional classroom, which was divided into different learning environments, specifically designed for static, movement, materials and new technologies. The setting of the students' tables and of the teacher's desk - which is no longer an "active mediator" in high school [5] - was rearranged in order to allow all students to play an active part in the learning experience. Throughout a few weeks, the new learning environment based on the "capability approach" [6] made it possible to set [7] the specific analogical languages of that student with intellectual disability - such as images, pictures, charts, cards, drawings, videos, concept maps - allowing the whole class to experience a laboratory learning training. Cognitive tests proved that the experimental classes managed to develop better learning processes in specific cognitive domains. Furthermore, the socio-metric test results, which were recorded in a few socio-grams, showed an increase in popularity and involvement of the students with intellectual disability.
\end{abstract}

Keywords: intellectual disability, learning environment, analogical languages, laboratory

Cite This Article: Bagnariol Silvio, "Construction of an Inclusive Learning Environment: Towards a New Ecological Class." American Journal of Educational Research, vol. 3, no. 8 (2015): 1005-1009. doi: 10.12691/education-3-8-9.

\section{Introduction}

The data of the year 2013/2014, show us that the students with disabilities - 222917 of all school levels - in Italy, grew by $3.2 \%$ over the previous school year and the $66.7 \%$ of them have a level of "intellectual disability" [8].

The broad meaning of "intellectual disability" used here, it is related to all the forms of mental deficiency, mild or severe, developed before $18^{\text {th }}$ years [9].

According to the Atlas project of the WHO, in the world different terms are being used to refer to the same condition of intellectual disabilities: "mental retardation" (76\%), "intellectual disability" (58.6\%), “mental disability” (39.7\%) and "learning disabilities" (39\%) [10].

Mental retardation is a serious mind-altering that occurs as a global psychiatric syndrome: the development of these individuals is characterized by being slower than the typical one and with defective development of the abstractive functions, of the knowledge and adaptation [9].

The thought remains highly dependent on the experience and representation of it, perceptions can not be generalized, the language is poor and stereotyped [11].
Since the year 2005, the section of psychiatry of mental retardation of the World Psychiatric Association (WPA) and the European Association for Mental Health in Intellectual Disability (EAMH-ID) have adopted the term "intellectual disability" [12].

However, the term mental retardation is still prevalent in the clinical and administrative contexts, instead the term intellectual disability is more used in the community contexts [12].

The underlying conditions that cause the intellectual disability are universal, but the resulting conditions of these people depend on particular social contexts [13].

In Italy, according to the recent definition of the International Classification of Functioning, Disability and Health (ICF) [13], the intellectual disability is seen as the result of a complex system of biopsychosocial factors: the physical conditions, the functions and structures of the body, the contextual and environmental factors, the participation.

All these factors can interact with each other in a positive or negative way on the school inclusion [9].

In particular, the environmental and contextual factors of the ICF are considered critical to increase the activity and participation of these school students too. 
In this paper are presented the results of an experimental research, in which some students of a secondary school with intellectual disability have taken part with their classmates, in the same suitable learning environment [3].

In order to satisfy the Special Educational Needs, all the students shared some tasks in an analogical learning laboratory.

\section{School Inclusion as Environmental Approach}

The "Italian approach to disability" [15] is characterized by a growing active participation of the students with intellectual disability in the mainstream classes, so that the inclusive approach evolved from assimilation to integration and, in these last years, to inclusion [16]. As Ianes supports [1], integration is not at issue, yet it is often unsatisfactory: "in spite of the Italian innovative legislations on school inclusion, integration still has problems in the practical experiences" [17].

The inclusion process is founded on the mutual support among all the students, on the active participation of the student with disabilities [18] and on giving equal opportunities [19] in the same learning context [20].

In order to construct an inclusive environment [21] the common and the special needs should be considered together to realize a "special normality" [22].

Indeed, contextual and environmental factors of the ICF paradigm [14] are so important to influence learning and relationship qualities of all students and also to reduce, or amplify, the handicap of the students with disabilities [23].

Recent researches [2,24] point out as the percentage of the students with disabilities that study in common situations, decreases as the students grow. In particular, secondary school students often learn in separated contexts, in classrooms far from their classmates.

Moreover, according to Zigler, intellectual disability is the product of genetic and environmental factors [25], so it is important to modify the environmental elements to try to reduce their learning difficulties.

The students with intellectual disabilities make use of a concrete thought, they need to learn by perceptive elements [26] and they often encounter resistances in the verbal language, in the lecture skills and in the lexical and phonological development $[27,28]$.

A learning environment should promote the process of the abstraction and comprehension of the reality through the construction of analogical [29] behavior, objects and performances in a common learning situation.

\section{Materials and Methods}

The classes, chosen for the experimental research, belong to a high school in the northern Italy.

Four students with intellectual disability and their own classmates formed the experimental group $(\mathrm{N}=61)$.

The same number of students with and without disabilities formed the control group.

The Special Educational Needs of the students with intellectual disability of the experimental group, the learning environment, the classmates mediation and the tools, have been planned as a single pedagogical configuration. [30] Here the analogical laboratory has been placed [7] in an ecological modality [4].

Instead, the students of the control group went on with the usual setting didactics and ways of learning of the class.

The research wants to verify if a training laboratory with analogical languages in a common framework improves the learning and the sociality of the students with intellectual disabilities and of the whole class.

In particular we expected that:

- the students with intellectual disabilities improve their processes of comprehension, for the reading literacy, knowing and applying, for the mathematical and science literacy.

- the students without intellectual disabilities improve their processes of: explaining, for the reading literacy, reproducing and connecting, for the mathematic literacy, providing scientific explanation to phenomena, for the science literacy.

- the students with intellectual disabilities improve their level of popularity, and the general level of their classmates increase too.

The cognitive processes were chosen on the basis of educational needs of all the students and they are evaluated with their school teachers.

The students of both groups answered two set-tests: a pre-test before the experimental training and a post-test.

The items of these tests were chosen with the same difficulty and in order to misure the same processes.

The set-test of the students without disabilities was composed by some items of the released compendium "OECD-PISA" - Programme for International Student Assessment [31].

PISA provides that the adopted assessment tools are valid internationally, have solid methodological basis, give due emphasis to the effectiveness of educational action. The tests are designed to assess to what extent students can apply their knowledge to real-life situations and be equipped for full participation in society [32].

For this research the tests were chosen from all the three literacies: the reading literacy, the mathematics literacy and the science literacy, divided in Continuous and Non-Continuous format.

The cognitive processes investigated by the items for the students whithout disabilities are: explaining, for reading literacy, reproducing and connecting, for the mathematic literacy, providing scientific explanation to phenomena, for the science literacy.

The set-test of students with intellectual disabilities was appropriately tailored on their specific cognitive level.

Some released practices of TIMMS 2007 Assessment Frameworks- "Trends in International Mathematics and Science Study" by the International Association for the Evaluation of Educational Assessment (IEA) [33] - were used to investigate the mathematical and science literacy.

The TIMSS Assessment Frameworks 2007 [34], were developed through an international consensus-building process involving input from experts in education, mathematics, science, and measurement.

Some standardized "MT" tests [35,36] of the Psychological research group of Padua were used to investigate the reading comprehension. 
The cognitive processes investigated by the items for these students are: comprehension for the reading literacy, knowing and applying for the mathematical and science literacy. Also for these students, all the tests were divided in Continuous and Non-Continuous format.

In order to investigate the social domain, all the students answered to the question: "Who would you like as your classmate?". Each student expressed four preferences; the results are recorded also in a few sociograms.

\section{Towards a New Ecological Class}

\subsection{The New Learning Environment}

Concurring with Vayer and Duval [4], the environmental design of an ecological class is the planning of all the material data that subsequently create the condition for the relationships into the classroom.

First of all, the environmental design is the first practical action [25] defining the different kind of spaces where to allocate the different material data of the analogical laboratory.

The construction of the new ecological class involved the following steps:

a) design of functional places;

b) design of the movements;

c) design of material data.

a) Design of functional places. In this step, some subareas were identified to allocate the most relevant functions for the fulfilment of the laboratory. These functional areas must be easily identifiable, well characterized, and so much distinguishable to be considered functional places by all students.

The students with intellectual disability (I.D. in Figure 1) require an environment that does not have to be random but ordered and structured [25] and, according with the capability approach [6], these students can easily combine their internal resources with those they find in the environment.

The space of the class has been divided here in two functional places: the analogic area (A in Figure 1) and the work group area (B in Figure 1). The analogic space is the core of the new class, it has an inverted $T$ form and it is divided in others two sub-areas: the materials' space and the new technologies' space $\left(A_{1}\right.$ and $A_{2}$ in Figure 1$)$.

The two functional places, due to their agentive property [37], were the first "mediator" [5] helpful for the students.

b) Design of movements. In the secondary school, the movement of the students is rarely taken into account as an element of the learning. The solution here adopted proposes to divide the space of the new class into two components of the movement: the space of movements and the static space.

The students must be able to know where they have to move less and where they can move actively and explore the entire new environment.

In this way, all students have perceived the new classroom as a capability environment and, stimulated by cognitive tasks, they have explored it in search of materials and tools that they have seen fit to the task's resolution.
Compared to a traditional learning experience, being able to move in the new learning environment has allowed the increase of the participation of the students with intellectual disability too.

c) Design of material data. Students with intellectual disability find real barriers to learn in the traditional setting of classroom, for example in the disposition of benches, professor's desk and shelves.

In order to facilitate the learning and the movement inside and out the groups, the benches were arranged in small groups along the perimeter of the classroom in a fishbone form.

This solution avoids the students to get distracted with the students in the other groups and allows them to concentrate better on the task.

The professor's desk - deprived of any institutional meaning - was put in the middle of the analogic area with other benches: here the students were able to find all types of materials, colours and papers (1, 2 and 3 in Figure 1).

In the short side of the analogic area, the students could use some desktop computers and one laptop, a printer, a digital camera and an interactive whiteboard (4, 5 and 6 in Figure 1).

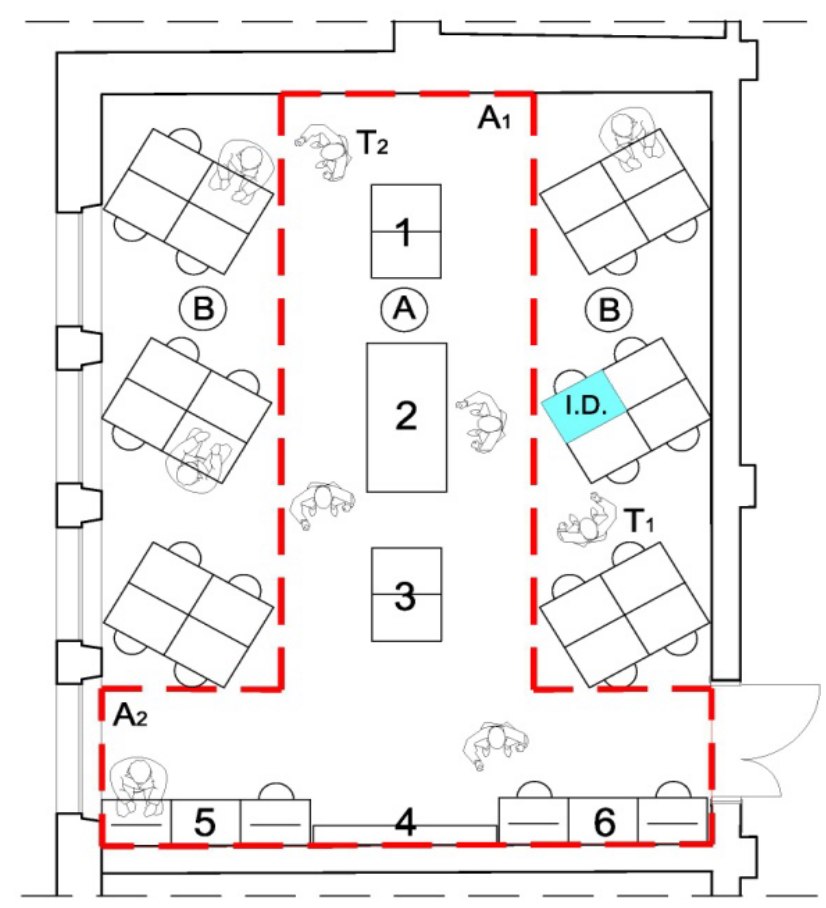

Figure 1. Design of the new ecological class

A: analogic area

$\mathrm{A}_{1}$ : materials' space

1 : colored cards and posters

2 : scissors, glue, stationery

3 : colored pencils, tempera, markers

$\mathrm{A}_{2}$ : new technologies' space

4 : Interactive multimedia Whiteboard

5-6: Computers and new technologies

$\mathrm{B}$ : work group area

$\mathrm{T}_{1}$ : teacher

$\mathrm{T}_{2}$ : support teacher

ID : student with Intellectual Disabilities

\subsection{The Analogical Laboratory}

In this new learning environment, the experimental group took part to the analogical training twice a week for two months, in order to solve some exercises that were 
selected from the book: "Prepare for the OECD-PISA tests" [38]. The alcohol abuse it has been chosen as the laboratory theme because it is a problem particularly felt by the teenagers of the school territory.

All students were free to choose the analogical languages that better fitted to realize each activity inside their mini-group.

Students with intellectual disabilities have given their support to many activities, according to their abilities and skills.

They solved the exercises in little groups using their favourite analogical tools, which were placed in the analogical zone (Figure 1) of the new ecological classroom.

The activities laboratory of the students were: do $a$ brainstorming session, build a word-cloud, build a concept map, compare charts and tables, make a creative elaborate.

In the creative activity the students with intellectual disabilities could express their specific talent [39]: some of them designed a billboard or a table, other took photographs and made photomontages, and other realized a simple movie with a movie maker program.

The agentive processes [37] developed during the analogical laboratory were: writing, drawing, cutting, ordering the word-cloud, making a simple conceptual maps also with the computer.

All the activities had been made with the support and participation of all the components of the mini-group.

At the end of the analogical training, the creative works were shown and explained to all the classmates.

\section{Results}

\subsection{Cognitive Results}

For the analysis of the results of the written test in PRE and POST there was used the software tool SPSS. It permitted to analyse the data from a statistical point of view and apply statistical tests. There were compared the number of right questions answered in each written test in order to understand if there were significant differences between the results in PRE and POST. The analysed data followed a normal distribution; therefore, it was possible to determine if the two sets of data (PRE and POST) were significantly different with the $T$ statistical test. It was applied as a two sample location test with null hypothesis - there is no difference between the number of right answers and alternative hypothesis - there is difference between the number of right answers.

The statistical significance of the T-test was set to 5\%.

All the students of the experimental group have obtained a significant difference between PRE and POST test in the learning domain, higher in the non-continuous questions compared to the continuous questions.

The students without disability of the experimental group have increased the number of correct answers by the $66 \%, 52 \%$ and $39 \%$ respectively for the literacy in reading, mathematics and science. The total increase of these students is the $52 \%$.

For these students the cognitive processes that have increased are explaining in the reading literacy (66\%) and interpreting in the mathematic literacy (95\%).
The students with intellectual disability of the experimental group have increased the number of correct answers by $44 \%, 33 \%$ and $50 \%$, respectively for the literacy in reading, mathematics and science.

The total increase of these students is the $42 \%$.

For these students the cognitive processes that have increased are reading comprehension (44\%), knowing (51\%) and applying (49\%).

Overall, the students with intellectual disabilities have increased their results less than those of their classmates.

In particular, the students with minor gravity have obtained better results compared to the students with severe intellectual disabilities.

This result is explainable due to the characteristics of the intellectual disability that requires much longer times and over repetition to consolidate learning and socialization.

The students of the control group hasn't obtained significant differences.

\subsection{Social Results}

The social results reported in some socio-grams have measured the level of popularity of each student and of the whole class.

For the students with disabilities of the experimental group, was evaluated the difference of the absolute and the weighed choices. Each of these student has improved the number of absolute and weighted choices received.

In order to evaluate the whole class, it was used the analysis of variance: the results of the experimental classes show a better distribution of the scores of all these students.

\section{Conclusions}

If the "Italian approach to disability" [15] doesn't remain only an advanced law model but becomes a concrete didactic work, you can obtain very positive results.

Indeed, the ecological and environmental approach [4] to scholastic inclusion, proposed here, has produced an improvements in the cognitive and relational domains of the students in the experimental group.

The common learning situation of the analogic laboratory was able to develop some cognitive and social processes in all the students, also in those with intellectual disabilities.

However, these results were achieved by developing some inclusive expertises such as: knowing how to design common and agentive learning situation [7]; improving the skills of all students, even of those with mind difficulty; evaluating the importance of analogical languages for cognitive development [29]; placing these languages at the center of the learning situation.

This inclusive approach has been realized considering the learning environment, the classmates and the mediation tools, all planned as a "single pedagogical configuration" [30].

Unexpected results could be obtained by carrying out additional common learning situations, trying an other learning setting, developing different activities and promoting other agentive and cognitive processes. 


\section{References}

[1] Ianes, D., Note a margine del Rapporto: Gli alunni con disabilità nella scuola italiana, bilancio e proposte, in "Difficoltà di apprendimento”, vol. 17, n. 1, pp. 21-32, Oct. 2011.

[2] Canevaro, A., D'Alonzo, L and Ianes, D., L'integrazione scolastica dal 1997 al 2007. Risultati di una ricerca attraverso lo sguardo delle famiglie, Bolzano: University Press, 2007.

[3] Montessori, M., La mente del bambino, 8th ed, Milano: Garzanti Editore, 2014.

[4] Vayer, P. and Duval, A., “L’organizzazione relazionale è sostenuta dall'organizzazione materiale”, in Verso un'ecologia della classe. Ricerche sugli arredi, gli spazi, i territori e gli oggetti della classe, Roma: Armando Editore, 1992.

[5] Damiano, E., “L'insegnamento come mediazione”, in La mediazione didattica. Per una teoria dell'insegnamento, Milano: Franco Angeli, pp.141-206, 2013.

[6] Nussbaumm, M.C., Creating Capabilities. The Human Development Approach, Cambridge - London: The Belknap Press of Harvard University Press, 2011.

[7] Lave, J. and Wenger, E., Situated Learning. Legitimate peripheral participation. Cambridge: Cambridge University Press, 1991.

[8] Ministry of Education, University and Research, L'integrazione scolastica degli alunni con disabilità dati statistici A.S. 2012/2013. Available:

http://hubmiur.pubblica.istruzione.it/web/ministero/focus121113. [Accessed May 17, 2015].

[9] Vianello, R., Disabilità intellettive. Parma: Spiaggiari, 2008.

[10] World Health Organization, Atlas: Global resources for person with intellectual disabilities. Geneva, 2007. available: http://www.who.int/mental_health/evidence/atlas/en/ [Accessed Jun 21, 2015].

[11] Pfanner, P. and Marcheschi, M., Il ritardo mentale. Capire e curare una grave malattia della mente. Bologna: il Mulino.

[12] Castellani, A., La Malfa, G., Manzotti, S., Monchieri, S., Nardocci, F., and Ruggerini, C. (Eds), La promozione della salute mentale nella disabilità intelletiva. Trento: Erickson, 2010.

[13] Felce, D., Both accurate interpretation of deinstitutionalization and a postinstitutional research agenda are needed, Mental retardation, vol 44, 5, 375-382, 2006

[14] World Health Organization, International Classification of Functioning, Disability and Health. Geneva, 2001.

[15] Piazza, V., Maria Montessori. La via italiana all’handicap. Trento: Erickson, 2004.

[16] Nocera, S., Inserimento, integrazione, inclusione...Parole che cambiano, o situazioni nuove? Available: http://www.fondazionegualandi.it/inserimento-integrazioneinclusione/. [Accessed May 21, 2015].

[17] Ianes, D., and Macchia, V., La didattica per i Bisogni Educativi Speciali, Trento: Erickson, 2008.

[18] Parolin, I., Imparare ad includere. Riflessioni ed esperienze per una scuola inclusiva, Trento: Erickson, 2010.

[19] Booth, T., and Ainscow, M., ”Un approccio inclusivo per lo sviluppo della scuola”, L'index per l'inclusione. Trento: Erickson, pp. 107-122, 2008.

[20] Dovigo, F., Fare differenze, Indicatori per l'inclusione scolastica degli alunni con Bisogni Educativi Speciali. Trento: Erickson, 2007.
[21] Vasquez, A. and Oury, F., “L’organizzazione di una classe inclusiva. La pedagogia istituzionale per un ambiente educativo aperto ed efficace”. Trento: Erickson, 2011, pp 18-20.

[22] Ianes, D., Bisogni Educativi Speciali su base ICF: un passo verso la scuola inclusiva, 2013. available:

http://www.s-sipes.it/pdf/IANES_BES_2013.pdf [Accessed May 25, 2015].

[23] Caldin, R., "La pedagogia speciale, la sua situazione paradossa e il debito impagabile alla generazione che ci ha preceduto", in La ricerca pedagogica in Italia. Tra innovazione e internazionalizzazione. Lecce: PensaMultimedia, pp. 149-163, 2014,

[24] Canevaro, A., D’Alonzo, L., Ianes, D. and Caldin, R.,"I percorsi di integrazione degli alunni con disabilità, fra partecipazione piena, parziale e assente”, in L'integrazione scolastica nella percezione degli insegnanti. Trento: Erickson, , pp. 115-136, 2011

[25] Zigler, E., Education and psychological development, New Haven: Yale University Press, 1984.

[26] Lewin, K., A dinamic theory of personality, New York: McGrawHill Companies, 1935.

[27] Kernanand, K. T., Sharon, S., "Linguistic and cognitive ability of adults with Down syndrome and mental retardation of unknown etiology”, Journal of Communication Disorders, 29, 401-422. September-October, 1996.

[28] Van der Schuita, M., Segers, E., Van Balkoma, B., and Hans Verhoevena, L., "How cognitive factors affect language development in children with intellectual disabilities”, Research in Developmental Disabilities, 32, 1884-1894, September- October, 2011.

[29] Antonietti, A., Educare alla visualizzazione. Training immaginativo-spaziale per soggetti con ritardo mentale, Trento: Erickson, 1999.

[30] Baldacci, M., Trattato di pedagogia generale. Roma: Carocci, pp. 92-111, 2014.

[31] INVALSI, Compendio Prove OCSE-PISA per insegnanti. Available: http://www.invalsi.it/invalsi/ri/pisa2012.php?page=pisa2012_it_08 [Accessed July 12, 2015].

[32] Programme for International Student Assessment (PISA). Available: http://www.oecd.org/pisa/aboutpisa/ [Accessed July 12, 2015].

[33] INVALSI, Prove TIMSS 2007, rilasciate di matematica e scienze Available: http://www.invalsi.it/ric-int/timss2007/restitem.php. [Accessed July 12, 2015].

[34] The TIMSS 2007 Released Items. Available: http://timss.bc.edu/timss2007/items.html [Accessed July 12, 2015].

[35] Cornoldi, C. and Colpo, C. Nuove prove MT per la scuola media inferiore. Firenze: Organizzazioni Speciali, 1997.

[36] Cornoldi, C. and Colpo, C. Prove MT per la scuola media elementare 2. Firenze: Organizzazioni Speciali, 1995.

[37] Sen, A.K., Inequality Reexamined, Oxford: Oxford University press, 1992.

[38] Guasti, L., (Eds.), Prepararsi alle prove OCSE-PISA. Percorsi e unità didattiche multidisciplinari. Trento: Erickson, 2012.

[39] Margiotta, U. (Eds). Riforma del curricolo e formazione dei talenti. Linee metodologiche ed operative. Roma: Armando, 1997. 